\title{
LA POSFOTOGRAFÍA COMO UNA NUEVA GALAXIA DE LO IMAGINARIO: ANÁLISIS DESDE LA HERMENÉUTICA PROFUNDA
}

\section{POS-PHOTOGRAPHY AS NEW GALAXY OF IMAGINATION: ANALYSIS FROM THE DEEP HERMENEUTICS}

\author{
Jorge Alberto Lizama Mendoza \\ Doctor en Ciencias Políticas y Sociales con especialidad en Comunicación \\ por la Universidad Nacional Autónoma de México. \\ Director de Cybermedios.org \\ lizamamendoza@gmail.com
}

\section{Resumen}

El presente artículo se enfoca al análisis que la imagen fotográfica ha experimentado con el surgimiento de las tecnologías digitales, las cuales han transformado sustancialmente su naturaleza, lenguaje y narrativa. A través de la metodología de la hermenéutica profunda se analizan escenarios del lenguaje digital de corte compositivo, morfológicos y de enunciación, que permiten entender el valor de la posfotografía como un elemento fundamental para la galaxia de lo imaginario.

Palabras clave: Hermenéutica profunda, posfotografía, lenguaje digital, imagen líquida, galaxia de lo imaginario.

\begin{abstract}
This article analyzes the changes that the photographic image has experimented with the emergence of digital technologies, which have substantially changed their nature, language and narrative. Through the method of depth hermeneutics, analyzes the digital language in their composition values, morphological and enunciation, which allow to understand the value of the post-photography as a key element in the galaxy of imagination.
\end{abstract}

Key words: Depth hermeneutics, post-photography, digital language, liquid image, galaxy of the imagination

\section{Introducción}

El presente artículo se enfoca al análisis hermenéutico que la imagen 
fotográfica ha experimentado con el surgimiento de las tecnologías digitales, las cuales han transformado sustancialmente su naturaleza, lenguaje y narrativa.

Ciertamente, la convergencia tecnológica entre las telecomunicaciones, la informática y las memorias multimedia han democratizado no sólo los escenarios del software especializado para tratar/modificar/mutar la esencia original de la imagen ${ }^{1}$; además, han logrado que dicha imagen intervenida se difunda de manera viral a través de Internet. En este escenario, si antes la fotografía analógica estaba basada en nociones que parecían universales como el grano, el aura y la reproductibilidad mecánica propuesta por Benjamín (2003); ahora está supeditada a figuras como el píxel, lo posaurático y la reproductibilidad 2.0. Si antes estaba basada en el eje de lo real; ahora ha dado paso a una nueva dimensión de lo imaginario.

En tal sentido, este artículo recupera el método de la hermenéutica profunda (Thompson, 2002), en particular el análisis formal / discursivo de la construcción simbólica para:

a) Analizar y caracterizar la nueva edad ontológica de la imagen fotográfica, la llamada posfotografía; que surge a partir de la llegada e intervención de las tecnologías digitales.

b) Proponer una serie de indicadores a nivel de metanarrativa y de galaxia de lo imaginario, que ayuden a entender la importancia que tiene la posfotografía en los procesos de representación visual actual.

\section{Posfotografía: EI nuevo insecto digital}

La hermenéutica profunda, entendida como el arte de la interpretación realizado por seres interpretativos, se basa en analizar las construcciones simbólicas de manera discursiva a través de indicadores como la semiótica, lo conversacional, lo narrativo, lo sintáctico, lo argumentativo y lo discursivo. Mediante estás vías es posible ubicar, definir y caracterizar formas simbólicas compartidas en la sociedad. Como señala Thompson (2002, p. 404):

La idea que subyace en la hermenéutica profunda es que, en la investigación social y en otros campos, el proceso de investigación puede ser, y de hecho exige ser, mediado por una amplia gama de métodos explicativos u "objetivantes" (...) Por tanto, la 'explicación' y la

\footnotetext{
${ }^{1}$ Sobre el tema de la imagen digital y sus transformaciones ontológicas y hermenéuticas han comenzado a difundirse un gran número de aportes conceptuales. En el apartado bibliográfico de este trabajo el lector podrá encontrar algunas propuestas destacadas.
} 
'interpretación' no deberían ser consideradas, como a veces se hace, como métodos mutuamente excluyentes o radicalmente antitéticos; más bien, pueden tratarse como momentos complementarios en una teoría interpretativa comprehensiva, como pasos que se apoyan mutuamente en un 'marco hermenéutico único?

En el caso de la imagen fotográfica, ya sea en su naturaleza analógica o digital, se está en un primer momento ante un problema que inicia con un abordaje metodológico de corte semiótico, mismo que después derivará en otros de naturaleza narrativa y discursiva.

Basándose en el primer momento de todos, el semiótico, resulta oportuno acotar tres edades ontológicas que la imagen ha venido experimentando a lo largo del tiempo:

Si en sus orígenes la fotografía tenía, como señala Barthes (2009), la figura ideal del ESPEJO (la imagen debe ser lo más fiel posible a la realidad = el significante es igual al significado) y a la HUELLA (la imagen sólo puede dar indicadores de interpretación $=$ el significante provoca distintos significados); ahora, como bien propone Fontcuberta (2001), se decanta por lo LIQUIDO (el significante y el significado pueden ser intervenidos): la imagen, a través de lo digital, puede continuamente modificarse, recrearse, adaptarse, combinarse, flexibilizarse, etc; dando nacimiento a lo que muchos llaman posfotografía.

Cabe destacar que en adelante se recupera el término de posfotografía sugerido por Fontcuberta (2001) como base para proponer la siguiente definición conceptual: una representación nacida de la composición digital, de ontología líquida, que genera una serie de disparadores transicionales a lo imaginario, disparadores que pueden o no alejarse del ejercicio del artificio y buscan provocar una nueva agencia de sentido en el espectador. Bajo la óptica de la posfotografía es posible retocar/transformar/agregar elementos compositivos nuevos a una fotografía tradicional, actuando como un segundo obturador de significación para el espectador.

Ciertamente, en términos de construcción simbólica se puede aseverar que la posfotografía suma un segundo obturador al diafragma de la cámara fotográfica tradicional. Este segundo obturador está hecho de píxeles que a su vez son tratados por software especializado, una conjunción que dota a la imagen de una apertura permanente a la manipulación y a la interpretación: 
- Si la fotografía tradicional apela al grano fotográfico, la posfotografía apela al píxel.

- Si la fotografía tradicional apela al contenido literal, la posfotografia apela a la saturación múltiple.

- Si la fotografía tradicional apela a la imagen civilizada (única e intocable), la posfotografía apela a la imagen antropófaga (que devora a otras imágenes para articular su propia naturaleza).

- Si la fotografía apela a Dios para guiar la mirada y el dedo del fotógrafo, la posfotografía apela al Deux Ex Machina (el Dios de la máquina) para definir gran parte de la creación de imagen.

Hoy en día la llegada e impacto cultural de la posfotografía es tal, que ha provocado un debate intenso entre dos tradiciones artísticas opuestas en la manera de entender la imagen:

a) Por un lado, las ópticas que asumen como natural la separación de las humanidades ante la ciencia y la tecnología, teniendo como herencia fundamental el diagnóstico artesanal de Benjamín (2003) de la reproductibilidad y el fin del aura.

Para esta tradición, la posfotografía puede ser entendida como una marabunta, una plaga de insectos digitales que ha venido a invadir y corromper prácticamente toda la ecología de representación de la fotografía tradicional; desde el arte, el periodismo, la publicidad, los retratos familiares, etc. ¿El resultado? Un notable incremento en los índices de lo kitsch, el esteticismo, la belleza no humana (como las modelos irreales de las revistas de moda), el simulacro del tiempo/espacio. Como indica Fontcuberta, 2001, p. 43)

"Estamos siendo espectadores privilegiados de una nueva pérdida del aura de la obra de arte digital, como consecuencia de la introducción de las tecnologías de la información y la comunicación en el ámbito de la producción cultural contemporánea. Ciertamente, hemos dejado atrás el modelo de producción cultural que engendró la modernidad. El nuestro es un nuevo modelo estructurado a partir de unas nuevas tecnologías y unos nuevos soportes que, concebidos como medios de expresión artística, están modificando la manera de producir, reproducir, difundir y consumir la obra, no ya mimética, mecánica y masivamente sino de un modo idéntico, digital y global." 
Esta pérdida del aura en la obra e imagen digital es, sin duda, el eje más sólido para impulsar una diferencia creativa insalvable entre los fotógrafos hechos bajo los métodos de la modernidad analógica y los hechos bajo la posmodernidad digital.

Sobre este punto cabe acotar que si bien los principios de Benjamín de lo auténtico, la unicidad y lo irrepetible funcionan hasta hoy en día como valores universales de la obra de arte; también es claro que dichos principios, como señala Argemi (2009), en gran medida están articulados bajo una mirada burguesa hacia el arte, donde es valor de cambio lo elitista, lo original y la mercancía única.

b) Por otra parte, están las agencias culturales que plantean la integración ya impostergable de las humanidades con la ciencia y la tecnología. Aquí, la tecnología no es sólo una herramienta de apoyo para la creación, sino el actor mismo que aporta sugerencias y dimensiones creativas en el desarrollo de la imagen.

En esta nueva dimensión creativa se transforman varios elementos inmiscuidos formalmente en el proceso; por ejemplo, la figura del público "consumidor" de la modernidad analógica, que sólo consumía signos pero que no los generaba; pasa a ser potencialmente la de un prosumidor (productor + consumidor) (Toffler, 1976) en la era posmoderna digital: alguien que ya no sólo consume signos, sino que ayudado e impulsado por los lenguajes del segundo obturador, puede producir, derivar, recombinar la imagen digital a partir de su propia experiencia simbólica.

Con la nueva ecuación que la soporta, articulada por productos líquidos y prosumidores, la posfotografía certifica sin duda que sigue siendo un "insecto digital" que lo devora todo; empero, su naturaleza no necesariamente está depositada en la construcción de artificios; sino en la búsqueda de la provocación y de lo imaginario; es decir, en la indagación de elementos que enriquezcan la semiosis de la imagen. El insecto digital puede ser una mosca o una abeja, todo depende de la forma con que uno se relacione con el Deux Ex Machina.

Bajo esta certeza, la discusión de la dimensión positiva e enriquecedora de la posfotografía debe entonces encaminarse a estudiar la galaxia de lo imaginario que trae consigo el insecto digital.

\section{La galaxia de lo imaginario: De la mosca a la abeja digital}


Uno de los mayores cuestionamientos que se le puede encontrar al sistema de significación de la posfotografía es que ha menudo se le utiliza para crear grandes fábricas de artificio, al punto que mucho de lo tratado por el segundo obturador parece no generar más que productos encaminados a alimentar la polución de simulacro e hiperrealidad alertadas por Jean Baudrillard (2007):

La revista "Nacional Geographic en español" de mayo de 2007 presenta en su portada una fotografía del "muro incómodo" que divide la frontera entre los EU y México; el tratamiento preciosista de la imagen, con un plano altamente rebuscado y un juego de luces y sombras exagerado con software de retoque, hacen pensar al que observa que se está una acrópolis griega o cuando menos ante un penal de primer mundo. Por su parte, el adelgazamiento que "Ralph Lauren" hizo de la modelo Filippa Hamilton a través de Photoshop, generó un gran número de críticas en octubre de 2009 debido a la estética "no humana" que la marca había construido y presentado como ideal de belleza.

Los índices de polución visual, de insectos digitales que contaminan todo el romanticismo de la imagen objetiva, parecen indicar que cuando el segundo obturador se utiliza para subrayar/incrementar/elevar el contenido aportado por los géneros propios de la fotografía tradicional no se obtiene un valor agregado, sino, recuperando a Baudrillard (2005), un valor-fractal, apoyado en una tautología cuya forma puede ser "la riqueza sin riqueza".

Pero la posfotografía no sólo se define por generar valor-fractal, también puede aportar valor-imaginación a la representación visual. Puede impulsar una galaxia de lo imaginario (Maffesoli, 2009) que sume nuevos elementos narrativos a la fotografía, fomentando la riqueza comprensiva, reflexiva y creativa de la imagen. En tal sentido, el valor más auténtico del segundo obturador no está depositado en desrrealizar la ontología propia de la imagenespejo o la imagen-huella; sino en inaugurar nuevas posibilidades de imaginación para la imagen liquida.

Citado lo anterior, a continuación, se proponen algunas dimensiones que pueden servir como ejes axiales para entender la construcción del valorimaginación de la posfotografía:

1- La metanarrativa morfológico-compositiva.

Toda imagen generada por computadora es una infografía, por tanto, hoy en día prácticamente cualquier persona tiene posibilidades de crear sus propias fotografías digitales pues nos encontramos inundados por la era del "pervasive computing", que se manifiesta en los costosos equipos reflex hasta las cámaras de teléfonos celulares. En esta era, crear una infografía no 
supone ningún reto destacable dado que su lógica está basada en seguir los pasos del primer obturador; empero, más difícil resulta aplicarle un tratamiento desde el segundo obturador, el del software.

Sólo desde el dominio del segundo obturador la imagen fotográfica puede adquirir una dimensión metanarrativa para el espectador, es decir, sumar a la capa de representación 1: la enunciativa que aporta el objeto/persona/paisaje que se haya decidido capturar (punto de vista físico, actitud de los personajes, integración del entorno, acción, mirada); una capa de representación 2, donde la intervención intencional y radical en los elementos morfológicos (línea, punto, plano-espacio, escala, forma, nitidez, iluminación, contraste, colores) y compositivos (perspectiva, ritmo, tensión, proporción, recorrido visual) sumen nuevas evocaciones narrativos a la imagen base.

\begin{tabular}{|l|l|}
\hline Capa 2: & $\begin{array}{l}\text { Intervención radical en los elementos morfológicos y compositivos (Segundo } \\
\text { obturador) }\end{array}$ \\
\hline Capa 1: & Elementos enunciativos (primer obturador) \\
\hline
\end{tabular}

La fotografía de una iguana plantea una primera dimensión narrativa en el campo de la enunciación, pero la fotografía de una iguana a la cual se le han intervenido los elementos morfológicos y compositivos para dotarla de un color verde fosforescente y que además esté caminando en una superficie con ausencia de colores, impulsa al espectador a plantearse otros escenarios narrativos: el animal es la consecuencia de los excesos de la radiación en un mundo gris que ya no posee colorido, el animal está pintado y forma parte de un performance visual...

En este punto cabe destacar que hay software que permite al lego intervenir los elementos morfológicos y compositivos de la imagen con tan sólo un par de clics, obteniendo fotografías que asemejan la representación de la pintura, el cómic o la toma con barrido de fondo. En estos ejercicios del mínimo esfuerzo no se asiste al nacimiento de una imagen provocadora $\mathrm{o}$ metanarrativa, sino a un mero artificio de "riqueza sin riqueza" dado que los efectos son tan planos y tan generalizados en Internet, que se asiste a una fórmula de masas.

Si Benjamín alertó acerca de la reproductibilidad en el aura misma de la obra, ahora habría que alertar sobre la reproductibilidad 2.0 en los efectos a nivel morfológico y compositivo de la imagen digital.

Así pues, una auténtica metanarrativa a nivel morfológico y compositivo, que apele a la provocación y no al artificio, está integrada por: 
a) la recuperación y dominio de una técnica digital de creación de imagen (el creador debe ir más allá de la seducción del primer clic),

b) la minería de creación de elementos visuales y modulares a través del uso de capas de trabajo en software como Photoshop (el creador debe construir distintos elementos visuales y contrastarlos en distintos planos visuales) y

c) la combinación de ambas vías para crear una imagen con un arduo trabajo y que es, por tanto, única en su propuesta de narración visual.

Aquí, el creador de la imagen entiende que el segundo obturador debe apelar a la metáfora de la abeja y no de la mosca. Por ejemplo, la técnica del HDR (high dinamic range) que consiste en tomar tres fotografías en distintos exposiciones (una subexpuesta, otra sobreexpuesta y otra con la exposición que demande el elemento visual a fotografiar) y luego unirlas mediante software especializado da como resultado una imagen de alto impacto narrativo: los elementos de la imagen por pequeños que sean adquieren presencia, el contraste y la definición está presente en todos los planos de la imagen y no sólo en el objeto enfocado, etc.

La técnica hdr puede problematizarse aún más utilizando 5 o 7 exposiciones en lugar de 3 y puede además ser sometido a un tratamiento en capas de Photoshop para intervenir sus elementos morfológicos y compositivos, la suma de una técnica más la intervención en capas arroja una imagen única en su creación y muy compleja en su elaboración.

Finalmente, basta decir que la metanarrativa morfológico-compositiva no busca generar imágenes fotográficas que sustituyan a la realidad, que den la impresión de ser verdaderas; contrariamente, busca dotar a lo real de un marco visual que promueva el imaginario.

2- La metanarrativa enunciativa-morfológico-compositiva.

Una segunda vía para crear valor-imaginación en la posfotografía está depositada en la intervención ya no sólo de los elementos morfológicos y compositivos, sino también en la intervención de los enunciativos.

\begin{tabular}{|c|l|}
\hline Capa 2: & $\begin{array}{l}\text { Intervención radical en los elementos morfológicos y compositivos (Segundo } \\
\text { obturador) }\end{array}$ \\
\hline Capa 1: & Intervención radical en los elementos enunciativos (Primer obturador) \\
\hline
\end{tabular}

Intervenir los elementos enunciativos (ya no sólo los morfológicos y compositivos) implica, como señala Marzal (2007), que la posfotografía 
accede a una capa de representación con un alto poder de impacto en lo ideológico:

A diferencia de otras propuestas metodológicas, nuestro análisis pone el acento en el estudio de los modos de articulación del punto de vista. En efecto, es frecuente encontrar análisis icónicos que ignoran el problema de la enunciación. Cualquier fotografía, en la medida en que representa una selección de la realidad, un lugar desde donde se realiza la toma fotográfica, presupone la existencia de una mirada enunciativa. El examen de esta cuestión tiene consecuencias muy notables para conocer la ideología implícita de la imagen, y la visión de mundo que transmite.

¿En qué sentido se puede plantear el impacto de intervención radical de la posfotografía en los elementos enunciativos y, por ende, en la galaxia de lo imaginario?

La respuesta puede encontrarse en algunas producciones /géneros / experimentos notables de la posfotografía como abeja, como provocador eficaz de la galaxia de lo imaginario:

a) La posfotografía como máquina prospectiva

La manipulación del género fotográfico del retrato para, por medio del software, acelerar los años artificialmente y envejecer a la persona en cuestión. En su forma de artificio, este ejercicio puede ser integrado al circuito del consumo publicitario: "Adquiera este producto y evite llegar a viejo"; empero, en su faceta de provocación ha sido uno de los elementos nodales en investigación criminalística pues personas desaparecidas, niños robados que no aparecen durante años, etc. pueden ser potencialmente ubicados mediante la técnica del envejecimiento provocado de manera digital.

En este caso se asiste a una manipulación de los elementos enunciativos para plantear un índice-huella cuya función puede ser estética o, más importante, social. Y probablemente, el ejemplo más puntual de la fotografía prospectiva sea el trabajo pionero de Nancy Burgson, Age Machine (1968), una instalación informática interactiva destinada a envejecer los rostros de quienes interactuaban con ella. Como refiere Fontcuberta (2001, p. 46)

Los retratos así envejecidos de BrokeShields, John Travolta, John Kennedy Jr. y otras celebridades fueron publicados en revistas de gran difusión (...) La culminación del proyecto llegó cuando el FBI 
contactó con Burson y Kramlich para utilizar la máquina de envejecer con el propósito de rastrear con mayor eficacia niños desaparecidos.

Aquí, el impacto del segundo obturador busca asumirse como la realidad misma, como representación de lo concreto pero sólo a futuro y con las dispensas obvias de su construcción: El futuro es la meta y la posfotografía el transporte... la realidad, el punto de partida...

b) La posfotografía de evocación histórica

$\mathrm{Si}$ en un primer momento la fotografía analógica no pudo capturar determinado hecho histórico, en un segundo momento la posfotografía puede regresar virtualmente el tiempo y puede evocar una imagen que sirva de indicador de cómo pudo haber transcurrido la acción.

No se trata de recrear el hecho (artificio), sino de evocar en el receptor/espectador una posible ruta simbólica, un disparador de lo imaginario, de cómo pudo haber ocurrido (provocación).

Esta especie de máquina del tiempo que mira al pasado ha dado paso a la evocación histórica, al uso del segundo obturador en su dimensión antropófaga para recrear un episodio histórico articulado por elementos visuales que pertenecen a distintos tiempo/espacio.

Fundamentalmente en el arte, está técnica basada en el uso de capas, filtros de color y textura ha dado como resultado ser testigo privilegiado de un evento donde no hay memoria visual. Por ejemplo, no existen o al menos no han sido difundidas fotos del 2 de octubre de 1968 en México, DF, donde un batallón y el ejército arremetieron contra cientos de estudiantes reunidos en una plaza, provocando un gran número de muertos y desaparecidos. Todo el archivo público responde a horas después del evento, donde se ve al victimado pero no al victimario en plena acción.

Ante este vacío, la posfotografía puede unir una panorámica de la Plaza de las Tres Culturas (donde ocurrió el hecho) y alguna protesta reprimida violentamente por el ejército y fusionarlas. ¿El resultado? No una recreación del hecho (artificio), pero si un aporte desde otro punto de vista (desde la mirada, por ejemplo, de los helicópteros que estuvieron allí y desde donde inicio todo) que suma un disparador 
imaginario a un acontecimiento altamente censurado en cuanto a lo visual (provocación).

c) La posfotografía como espacio fantasma

Una tercera dimensión de provocación de la posfotografía es la que tiene que ver con los espacios fantasma. El espacio fantasma se entiende aquí como un lugar que ha pasado desapercibido para muchos, ya sea por sus arquitectos así lo planearon o porque cometieron un error de diseño. Es un espacio que no se ve a simple vista y acceder a él es cuestión del azar, pero cuando se logra el cometido se está ante un punto de vista distinto, una reactualización visual, que enriquece el imaginario del mundo cotidiano.

Algunos ejemplos de espacios fantasmas son las intervenciones visuales que se hacen en comunidades rurales y apartadas de la modernidad que se caracterizan por estar libres de la polución de imágenes de las grandes urbes. Aquí la posfotografía no se utiliza para introducir a la comunidad un producto publicitario (artificio), sino para provocar un punto de vista distinto acerca de su entorno (provocación): Una serie de carteles anunciando una película cuyo título es el nombre mismo de la comunidad y acompañada de una foto del lugar hace pensar a los pobladores que efectivamente pronto verán una cinta que tienen como protagonista al lugar. Empero, todo es imaginario y el cartel sirve para que el poblador, ante una cinta que no llega nunca, inicie un proceso de reactualización, reflexionando sobre distintos puntos de vista (espacios fantasma) que puede contener su lugar de origen en el film: una comunidad unida, una comunidad fragmentada, una comunidad con múltiples tradiciones, una comunidad de realismo mágico...

\section{Conclusiones}

Sin duda, en este punto de exposición vale la pena destacar que el debate entre la fotografía tradicional contra la posfotografía es inútil y estéril: son sistemas de significación distintos: uno nació en la modernidad analógica bajo las figuras del espejo y el aura, el otro en la posmodernidad digital arropado por lo líquido y lo posaurático. Por tanto, no existe la pronosticada "muerte o destrucción de la fotografía tradicional", pues la posfotografía pertenece a una familia ontológica distinta de la imagen y su función no es 
aniquilar, sino traer consigo y sumar, otras dimensiones y figuras de representación.

En un segundo momento, es importante destacar que el nacimiento de la posfotografía ha contribuido de manera notable a la densificación progresiva de la imagen en la cultura occidental. Y dicha densificación está trazada no por lo imaginario y la vanguardia (abeja / provocación), sino en mayor medida por lo publicitario y por el impacto de primera plana (mosca / artificio). Probablemente, esta simplificación de las potencialidades de la imagen digital a los derroteros tradicionales del mercado y el espectáculo de masas es lo que evita que la primera goce de un carácter reflexivo y de experimentación fuera de los escenarios del arte, la estética o la interpretación de lo visual.

Finalmente, a nivel de galaxia de lo imaginario, es evidente que allí, donde la fotografía tradicional no puede pasar (porque no se le dio permiso, porque no llego a tiempo o porque no puede captar los espacios fantasma); la posfotografia puede pasar, descubrir e incluso evocar virtualmente la esencia de la situación en cuestión. La fotografía puede captar la realidad pero no lo imaginario; la posfotografía capta la realidad y da su propia interpretación de lo imaginario. Sin duda, estas nuevas figuras de innovación compositiva, morfológica y enunciativa de la imagen, que cumplen y suman funciones de representación visual más allá del artificio, son el verdadero eje de desarrollo y problematización teórica de la imagen liquida. Empero, de manera paradójica, la posfotografía contribuye axialmente a democratizar la producción acelerada de la imagen, pero no puede hacer lo mismo con sus nacientes procesos teóricos de lectura y recepción crítica, los cuales son aún más desconocidos e ignorados que los de la fotografía analógica.

Si en la galaxia de lo imaginario la abeja siempre es más importante que la mosca, en el discurso visual destinado a las masas la mosca siempre derrota a la abeja.

Figura 1: Diferencias ontológicas entre la fotografía y la posfotografía 


\begin{tabular}{|c|c|c|}
\hline Época & Modernidad analógica & Posmodernidad digital \\
\hline Naturaleza & Analógica / Plata & Digital / Silicio \\
\hline Estado Objetivable & Permanente & Transitorio \\
\hline Ontología & Espejo / Huella & Líquido \\
\hline Átomos & Grano fotográfico & Píxel \\
\hline Esencia & Aura & Posaurática \\
\hline Comportamiento & Civilizado & $\begin{array}{c}\text { * Mosca } \\
\text { * Abeja }\end{array}$ \\
\hline Insecto digital & $\mathrm{X}$ & $\begin{array}{c}\text { Radical en los aspectos } \\
\text { enunciativos, morfológico y } \\
\text { compositivo }\end{array}$ \\
\hline Intervención visual & Escasa & $\begin{array}{c}\text { Reproductibilidad 2.0 } \\
\text { Difusión }\end{array}$ \\
\hline Géneros & $\begin{array}{c}\text { Reproductibilidad } \\
\text { Mecánica }\end{array}$ & $\begin{array}{c}\text { Metanarrativos: } \\
\text { Máquina prospectiva, } \\
\text { evocación histórica, espacio } \\
\text { fantasma }\end{array}$ \\
\hline & paisaje, etc. & \multicolumn{2}{c}{}
\end{tabular}

Fuente: Elaboración propia a partir de distintas fuentes: Argemi, 2009; Barthes, 2009; Baudrillard, 2007; Benjamín, 2003; Costa, 2007 y Fontcuberta, 2001.

\section{Fuentes de Consulta}

- ARGEMI, Roger (2009) El arte digital, un arte postaurático. De la pérdida del aura al artista como postproductor en IV Congreso de la Cibersociedad 2009: crisis analógica, futuro digital, Grupo de trabajo D-27: media art / arte digital http://www.cibersociedad.net/congres2009/ (2009, agosto)

- BARTHES; Roland (2009) La cámara lúcida. Argentina: Paidós Iberoamérica

- BAUDRILLARD, Jean (2007) Cultura y Simulacro . Barcelona: Kairos

(2005) El complot del arte. Argentina:

Amorrortu

(2000) Pantalla total. Barcelona:

Anagrama.

- BENJAMIN, Walter (2003). La obra de arte en la época de su reproductibilidad técnica. México: Itaca. 
- COSTA; Joan (2007) Diseñar para los ojos. Madrid: Joan Costa

- DERY, Mark. (1998) Velocidad de escape. La Cibecultura en el final del siglo. Madrid: Siruela.

- FONTCUBERTA, John (2001) Después de la fotografía: identidades fugitivas en El Paseante. La revolución digital y sus dilemas. Madrid: Siruela

- GUBERN, Roman (1996) Del bisonte a la realidad virtual. La escena y el laberinto. Barcelona: Anagrama.

- LEVY, Pierre (1999) ¿Qué es lo virtual? Barcelona: Paidos Multimedia 10.

- MAFFESOLI, Michel (2009) Iconologías. Nuestras idolatri@s postmodernas Madrid: Península

- MARZAL, Javier. (2007) Cómo se lee una fotografía: interpretaciones de la mirada. Madrid: Cátedra

- RENAUD, Alain. "Comprender la imagen hoy. Nuevas Imágenes, Nuevo régimen de lo Visible, Nuevo Imaginario." en VV.AA. (1989) Videoculturas de fin de siglo. Madrid: Cátedra

- SONTAG, Susan (2007) Sobre la fotografía. México: Alfaguara

- THOMPSON, John (2002) Ideología y cultura moderna. México: UAM-Xochimilco

- $\quad$ TOFFLER, Alvin (1976) La tercera ola. Madrid: Plaza \& Janes 